\title{
Absence of aquaporin-4 water channels from kidneys of the desert rodent Dipodomys merriami merriami
}

\author{
YAN HUANG, ${ }^{1}$ RANDALL TRACY, ${ }^{2}$ GLENN E. WALSBERG,${ }^{2}$ ANTHONY MAKKINJE, ${ }^{3}$ \\ PINGKE FANG, ${ }^{1}$ DENNIS BROWN,${ }^{1}$ AND ALFRED N. VAN HOEK ${ }^{1}$ \\ ${ }^{1}$ Renal Unit and Program in Membrane Biology, Massachusetts General Hospital and \\ Harvard Medical School, Boston 02114; ${ }^{2}$ Department of Biology, Arizona State \\ University, Tempe, Arizona 85287; and ${ }^{3}$ Diabetes Unit, Massachusetts General \\ Hospital and Harvard Medical School, Charlestown, Massachusetts 02129
}

Received 17 August 2000; accepted in final form 17 January 2001

\begin{abstract}
Huang, Yan, Randall Tracy, Glenn E. Walsberg, Anthony Makkinje, Pingke Fang, Dennis Brown, and Alfred N. Van Hoek. Absence of aquaporin-4 water channels from kidneys of the desert rodent Dipodomys merriami merriami. Am J Physiol Renal Physiol 280: F794-F802, 2001.-Recently, we found that aquaporin-4 (AQP4) is expressed in the S3 segment of renal proximal tubules of mice but not in rat proximal tubules. Because mice have relatively larger papillae than rats, it was proposed that the renal distribution of AQP4 in various species could be related to their maximum urinary concentrating ability. Therefore, kidneys and other tissues of Merriam's desert kangaroo rat, Dipodomys merriami merriami, which produce extremely concentrated urine (up to $5,000 \mathrm{mosmol} / \mathrm{kgH}_{2} \mathrm{O}$ ), were examined for AQP4 expression and localization. Contrary to our expectation, AQP4 immunostaining was undetectable in any region of the kidney, and the absence of $\mathrm{AQP} 4$ protein was confirmed by Western blotting. By freeze fracture electron microscopy, orthogonal arrays of intramembraneous particles (OAPs) were not detectable in plasma membranes of principal cells and proximal tubules. However, AQP4 protein was readily detectable in gastric parietal and brain astroglial cells. Northern blotting failed to detect AQP4 mRNA in kangaroo rat kidneys, whereas both in situ hybridization and RT-PCR experiments did reveal AQP4 mRNA in collecting ducts and proximal tubules of the S3 segment. These results suggest that renal expression of AQP4 in the kangaroo rat kidney is regulated at the transcriptional or translational level, and the absence of AQP4 may be critical for the extreme urinary concentration that occurs in this species.
\end{abstract}

freeze fracture electron microscopy; immunocytochemistry; Merriam's kangaroo rat; in situ hybridization

THE AQUAPORINS ARE INTEGRAL membrane proteins that are responsible for facilitated transmembrane water transport in a variety of epithelial and nonepithelial cell types. In mammals, 10 homologous aquaporins have been described that have different and complex tissue distributions $(1-3,6,12,19,27,28)$. In the kidney, principal cells of the collecting duct contain three aquaporins: aquaporin-3 (AQP3) and AQP4 are

Address for reprint requests and other correspondence: A. N. Van Hoek, Renal Unit, Massachusetts General Hospital East, 149 13th St., Charlestown, MA 02129 (E-mail: vanhoek@receptor.mgh. harvard.edu). constitutive basolateral membrane water channels, whereas AQP2 is shuttled between intracellular vesicles and the plasma membrane in response to the antidiuretic hormone vasopressin. Although the role of AQP2 in urinary concentration is well established, the precise contribution of the basolateral water channels to this process is less well understood. AQP4-knockout mice have a fourfold decrease in transepithelial water permeability in the inner medullary collecting duct (4). However, the urinary concentrating mechanism was only marginally affected (25). This contrasts with the $90 \%$ reduction of the urinary concentrating capacity that occurs when AQP1 is deleted from the proximal tubule and thin descending limbs of Henle $(5,15)$.

A recent study from our laboratory suggested that in kidneys of mice, AQP4 was localized not only to principal cells of the collecting duct but also to basolateral membranes in the S3 segment of the proximal tubule (25). It was suggested that the small (10\%) reduction of the urinary concentrating capacity in AQP4-knockout mice could be related, at least in part, to deletion of AQP4 from the S3 segment. In contrast, deletion of AQP3 from principal cell basolateral membranes in AQP3 knockout mice from the same membranes had a profound effect on the urinary concentrating capacity (16), indicating that principal cell AQP4 may have only a minor role in urinary concentration. Because of species-dependent variation in the pattern of AQP4 expression in the kidney and its possible correlation with the relative size of papillae and urinary concentrating capacity, we hypothesized that this water channel might show even greater expression in kidneys of animals that can adapt to a limited supply of water by producing highly concentrated urine (25).

The desert kangaroo rat from the Sonoran Desert in Yuma County and Gila County, AZ, was selected for this study. This species is phylogenetically closely related to mice and Wistar rats but can concentrate its urine to a level greater than $4,500 \mathrm{mosmol} / \mathrm{kgH}_{2} \mathrm{O}$. In the laboratory, Dipodomys meriami merriami (D. mer-

The costs of publication of this article were defrayed in part by the payment of page charges. The article must therefore be hereby marked "advertisement" in accordance with 18 U.S.C. Section 1734 solely to indicate this fact. 
riami) could be maintained for longer than 6 mo on dry seeds and rolled oats without any access to water. Contrary to our hypothesis, AQP4 protein was undetectable in the kangaroo rat kidney, as assessed by immunocytochemistry and Western blotting. However, AQP4 mRNA was detectable in collecting duct principal cells and in proximal tubules by in situ hybridization and RT-PCR, whereas Northern blotting failed to detect AQP4 mRNA in kangaroo rat kidneys. These findings suggest that protein expression is downregulated at the transcriptional or translational level in these animals. The data from these kidney-specific AQP4 "natural knockout" animals, in which AQP4 protein was readily detectable in stomach and brain, strongly suggest that AQP4 is not a major contributor to the urinary concentrating mechanism in mammals.

\section{METHODS}

Tissue fixation and sectioning. Kidneys, stomach, and liver from the rodents were removed, sliced into two to four pieces, and fixed in $4 \%$ paraformaldehyde in $10 \mathrm{mM}$ sodium phosphate buffer, $\mathrm{pH} 7.4$, for $4 \mathrm{~h}$. Slices were washed and stored in PBS containing $0.02 \% \mathrm{NaN}_{3}$. For cryostat sectioning, slices were infiltrated with $30 \%$ sucrose in PBS, placed on a support in oxytetracycline compound (Sakura FineTek, Torrance, CA) and frozen. Cryostat sections $(3-5 \mu \mathrm{m})$ were mounted on Fisher Superfrost Plus (Fisher) microscope slides, air-dried, and stored at $-20^{\circ} \mathrm{C}$.

Immunocytochemistry. For immunocytochemistry, sections were rehydrated in PBS for 5 min and blocked with $1 \%$ BSA in PBS for $20 \mathrm{~min}$. Incubations with polyclonal AQP1 (1:500), AQP2 (1:100), AQP3 (1:200), AQP4 (1:100), AQP9 (1:200), and monoclonal $\mathrm{H}^{+} \mathrm{K}^{+}$-ATPase $(1: 1,000)$ and gp330/ megalin (1:200) primary antibodies were carried out for $1 \mathrm{~h}$ at room temperature. After $3 \times 5$-min washes in PBS, CY3conjugated goat-anti-rabbit secondary antibodies (1:800) and/or FITC-conjugated (1:60) or CY3-conjugated (1:800) donkey or chicken anti-mouse secondary antibodies in PBS were applied to the sections for a further $1 \mathrm{~h}$. In other experiments, biotinylated secondary antibodies were used with a ExtrAvidin Peroxidase Staining Kit (Sigma), followed by final development using the DAB Liquid Substrate Dropper System (Sigma), counter staining with Mayer's Hematoxylin, dehydration in graded ethanols, and clearance in $\mathrm{xy}-$ lene. Immunofluorescence-stained sections were mounted using a 1:1 mixture of Vectashield and $0.3 \mathrm{M}$ Tris $\cdot \mathrm{HCl}(\mathrm{pH}$ 8.9) before examination with a Nikon FXA epifluorescence microscope. The sections prepared by the ABC method were mounted with Cytoseal XYL (Stephens Scientific), and images were collected by conventional photography.

In situ hybridization. For in situ hybridization, sections were brought to room temperature and treated with $1 \mu \mathrm{g} / \mathrm{ml}$ of proteinase $\mathrm{K}$ (Boehringer Mannheim) in 0.1 M Tris, $0.05 \mathrm{M}$ EDTA, (pH 8.0) at $37^{\circ} \mathrm{C}$ for $15 \mathrm{~min}$. Sections were rinsed with various buffers according to the manufacturer's specifications: diethylpyrocarbonate- $\mathrm{H}_{2} \mathrm{O}$, PBS, $0.1 \mathrm{M}$ TEA, $0.25 \%$ acetic anhydride, and $2 \times$ standard sodium citrate (SSC; SSC buffer). Sections were hybridized with sense or antisense digoxigenin-labeled AQP4 cRNA probes, which were prepared from the linearized rat AQP4 cDNA (241 bp, 528-769) and conjugated with a digoxigenin-labeled-RNA labeling kit (SP6/T7) (Boehringer Mannheim) according to the manufacturer's protocol. Incubations were carried out at $42^{\circ} \mathrm{C}$ overnight, and subsequently the samples were washed using a graded series of SSC buffers at RT and $37^{\circ} \mathrm{C}$. Samples were incubated in a buffer that contained $2 \%$ BSA and $0.3 \%$ Triton $\mathrm{X}-100$ for $30 \mathrm{~min}$. It was followed by incubation with antidigoxigenin antibody coupled to alkaline phosphatase (Boehringer Mannheim) diluted 1:250 with the buffer, containing $1 \%$ normal BSA and $0.3 \%$ Triton X-100 for $2.5 \mathrm{~h}$ at RT, and developed with nitro blue tetrazolium/5-bromo4-chloro-3-indoyl phosphate. The sections were dehydrated in a graded series of ethanol solutions, cleared in xylene, and mounted with Cytoseal XYL (Stephens Scientific).
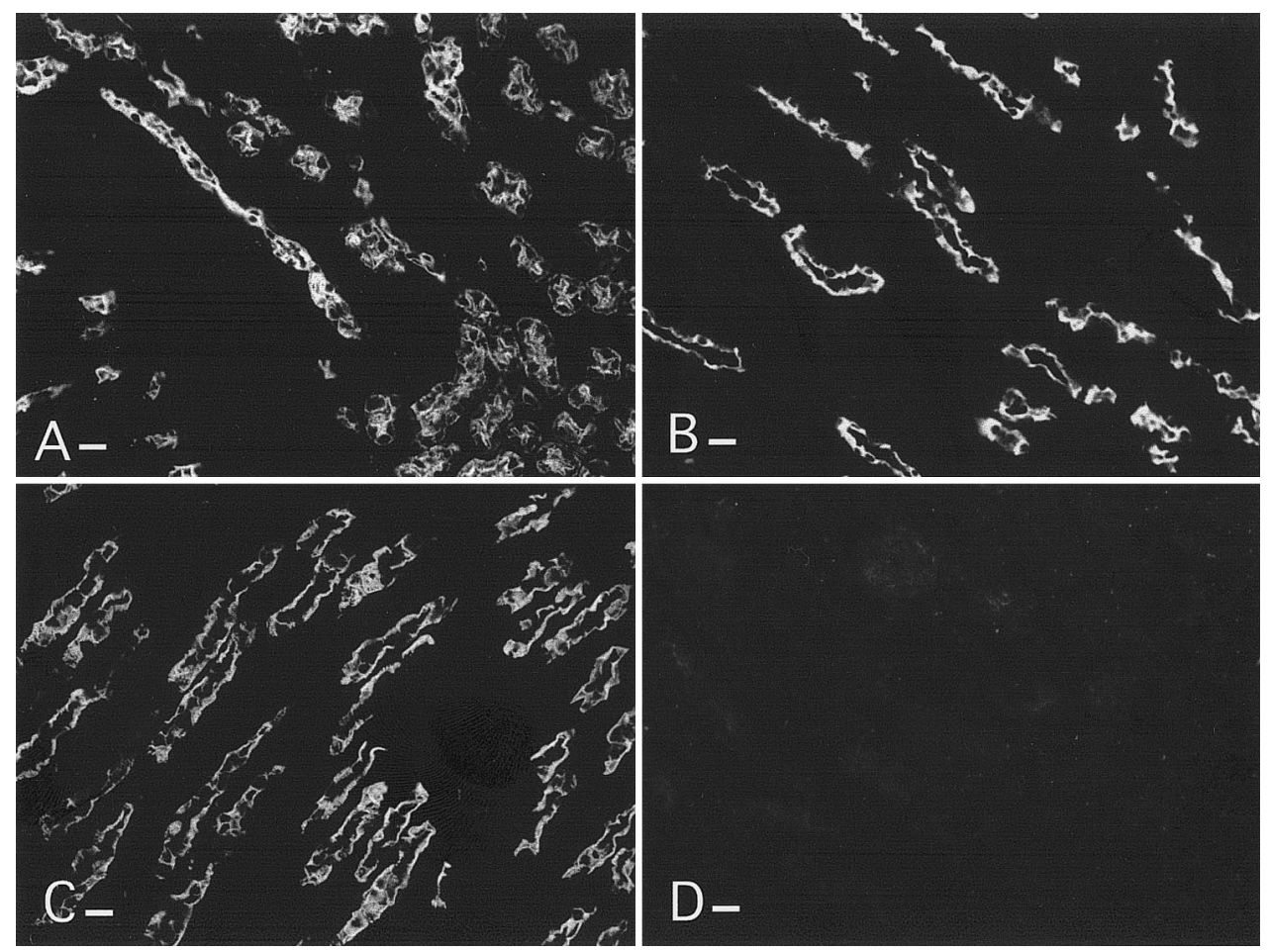

Fig. 1. Aquaporin immunocytochemistry on kidneys of the desert rodent Dipodomys merriami merriami. A: anti-aquaporin-1 (AQP1) antibody immunostaining of the medullary region in kidney, showing thin limbs of Henle (left) and proximal tubule (right) staining. $B$ : immunostaining with antiAQP2 antibody of apical membranes of inner medullary principal cells. $C$ : anti-AQP3 antibody immunostaining of basolateral membranes of inner medullary principal cells. $D$ : immunostaining of the inner medulla with anti-AQP4 antibody showing absence of staining. Bar $=15 \mu \mathrm{m}$. 
Immunoblotting (SDS-PAGE and Western blotting). Kidneys, stomach, and liver were removed and snap-frozen in liquid nitrogen. Frozen samples were placed in $0.2 \mathrm{ml}$ of lysis buffer [10 mM Tris, $\mathrm{pH} 8.0,150 \mathrm{mM} \mathrm{NaCl}, 5 \mathrm{mM}$ EDTA, 5 mM MEGTA, $1 \%$ Triton X-100, $1 \%$ octyl- $\beta$-D-glucoside (Anatrace), a complete protease inhibitor (Boehringer Mannheim), and $0.2 \mathrm{mM}$ phenylmethylsulfonyl fluoride]. The samples were homogenized by 10 strokes in a Dounce tissue grinder. Homogenates were spun at $12,000 \mathrm{~g}$ for $20 \mathrm{~min}$. Protein concentration of the supernatants was determined using the Bradford assay (Bio-Rad). SDS-gel electrophoresis and blotting were done with the NOVEX-XCell II Mini-Cell apparatus (NOVEX, San Diego, CA). Protein was added 2:1 to NuPAGE lithium dodecyl sulfate sample buffer and separated through a $12 \%$ Laemmli SDS polyacrylamide minigel by using NuPAGE-Tris-tricine ( $\mathrm{pH}$ 8.23) (NOVEX) as the electrode/running buffer. With NuPAGE transfer buffer $(\mathrm{pH}$ 7.2), proteins were blotted onto polyvinylidene difluoride (PVDF)-Immobilon membrane, 200- $\mu \mathrm{m}$ mesh, for $16 \mathrm{~h}$ at 10-25 V. The membranes were stained with Coomassie Brilliant Blue stain $[0.2 \%$ Coomassie Blue, $40 \%$ methanol $(\mathrm{MeOH}), 60 \%$ doubly distilled $\mathrm{H}_{2} \mathrm{O}$ ] then destained $(60 \%$ $\mathrm{MeOH}, 40 \%$ doubly distilled $\mathrm{H}_{2} \mathrm{O}$ ) and photographed before removing stain with $100 \% \mathrm{MeOH}$. Membranes were rewet in water and subjected to the "Western Breeze" protocol (NOVEX). Affinity-purified AQP4 antibody was diluted $1: 1,000$ in the manufacturer's primary antibody solution, and the PVDF membrane was incubated for $1.5 \mathrm{~h}$ at room temperature. Blots were developed using the chromogenic alkaline phosphatase assay.

Northern blotting. Kidneys, stomach, and liver were removed, washed in PBS and stored at $-20^{\circ} \mathrm{C}$ in RNAse Later (Ambion). After homogenization of the tissues, total RNA was prepared as described (21). Denaturing Northern gel electrophoresis (1.2\% agarose/2.2 $\mathrm{M}$ formaldehyde) was followed by transfer (21) onto N-Hybond (Amersham). A 650-bp Pst1 DNA fragment, corresponding to nucleotide residues 53-703 of AQP4 cDNA in psp64, was isolated and used for hybridization. A glyceraldehyde-3-phosphate dehydrogenase
(GAPDH) probe was obtained by digesting rat pTRI-glyceraldehyde-3-GAPDH (Ambion) with EcoR1, followed by random hexamer oligonucleotide labeling in the presence of $\left[\alpha-{ }^{32} \mathrm{P}\right] \mathrm{dCTP}(\mathrm{NEN}, 3 \mathrm{mCi} / \mathrm{ml}$ ) using a Klenow fragment according to the manufacturer's protocol (Pharmacia). Prehybridization and hybridization were carried out at $62^{\circ} \mathrm{C}$. After overnight hybridization, membranes were washed repeatedly with $2 \times \mathrm{SSC}, 0.1 \% \mathrm{SDS}$ at $62^{\circ} \mathrm{C}$, and placed on film.

$R T$-PCR. Mouse AQP4 primers were 5'-CACAGTGCCTGGGGGCCATTT-3' (forward) and 5'-TCTCCACGGTCAATGTCAATCACATGCA-3' (reverse). For the desert rodent, primers 5'-AAGCCAGGGAAGGCATGAGTG-3' (forward) and '5'-TGGAATCACAGCTGGCAAAAATAG-3' (reverse) were chosen based on a preliminary AQP4 sequence (unpublished). Five micrograms of total RNA were used and reverse transcription was carried out using the SuperScript FirstStrand synthesis system according to the manufacturer's protocol (GIBCO). One-tenth of each reaction product was subjected to PCR using PCR SuperMix High Fidelity (GIBCO) and appropriate cycling parameters.

Antibodies and controls. Antibodies against AQP2, AQP3, $\mathrm{AQP} 4$, and AQP9 were raised in rabbits against $\mathrm{COOH}-$ terminal peptides (15-18 amino acids) derived from the rat proteins (24). Antibodies against AQP1 were raised in rabbits against purified AQP1 protein from human erythrocytes (20). The peptides, including an AQP1 COOH-terminal peptide, were coupled to keyhole limpet hemocyanin before immunization of rabbits. Whole serum was affinity purified against the immunizing peptide using a Pierce affinity purification column kit (Pierce, Rockford, IL) according to the manufacturer's instructions. Control procedures for immunocytochemistry included incubation of the tissues with preimmune serum and preabsorption of the antibodies with the immunizing peptide.

Freeze-fracture electron microscopy. Tissue pieces were fixed in $2 \%$ glutaraldehyde for $2 \mathrm{~h}$ and washed and stored in PBS containing $0.02 \% \mathrm{NaN}_{3}$. Fragments $(0.5 \times 0.5 \mathrm{~cm} \times 1$ $\mathrm{mm}$ in size) of tissues were infiltrated with $30 \%$ glycerol in $0.1 \mathrm{M}$ cacodylate buffer $(\mathrm{pH}$ 7.4) overnight, placed on flat
Fig. 2. Immunocytochemistry of renal tissues of kangaroo rat and mouse. Anti-AQP4 antibody immunostaining is shown in red (using CY3-conjugated rabbit-secondary antibodies), and anti$\mathrm{H}^{+}$ATPase $(A, C)$, or anti-gp330/megalin $(B, D)$ antibodies are shown in green (using FITC-conjugated anti-chicken secondary antibodies; $A, C$ ) and antimouse secondary antibodies $(B, D)$. Note the absence of AQP4 staining in collecting ducts of the medulla $(A)$ and proximal tubules of the S3 segment $(B)$ of the kangaroo rat, contrary to presence of AQP4 staining $(C)$ and $(D)$ in similar regions of the mouse. $\mathrm{Bar}=15$ $\mu \mathrm{m}$.
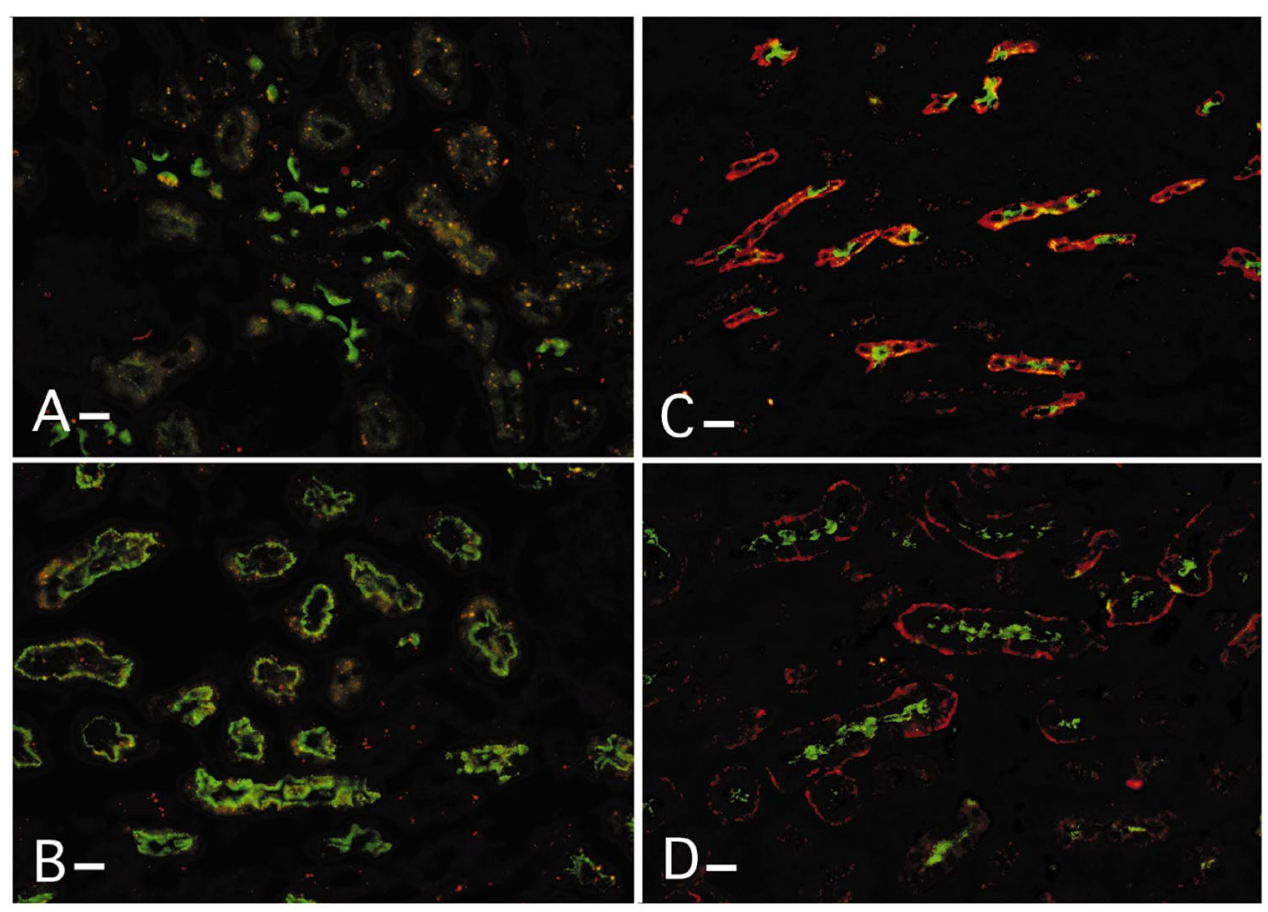

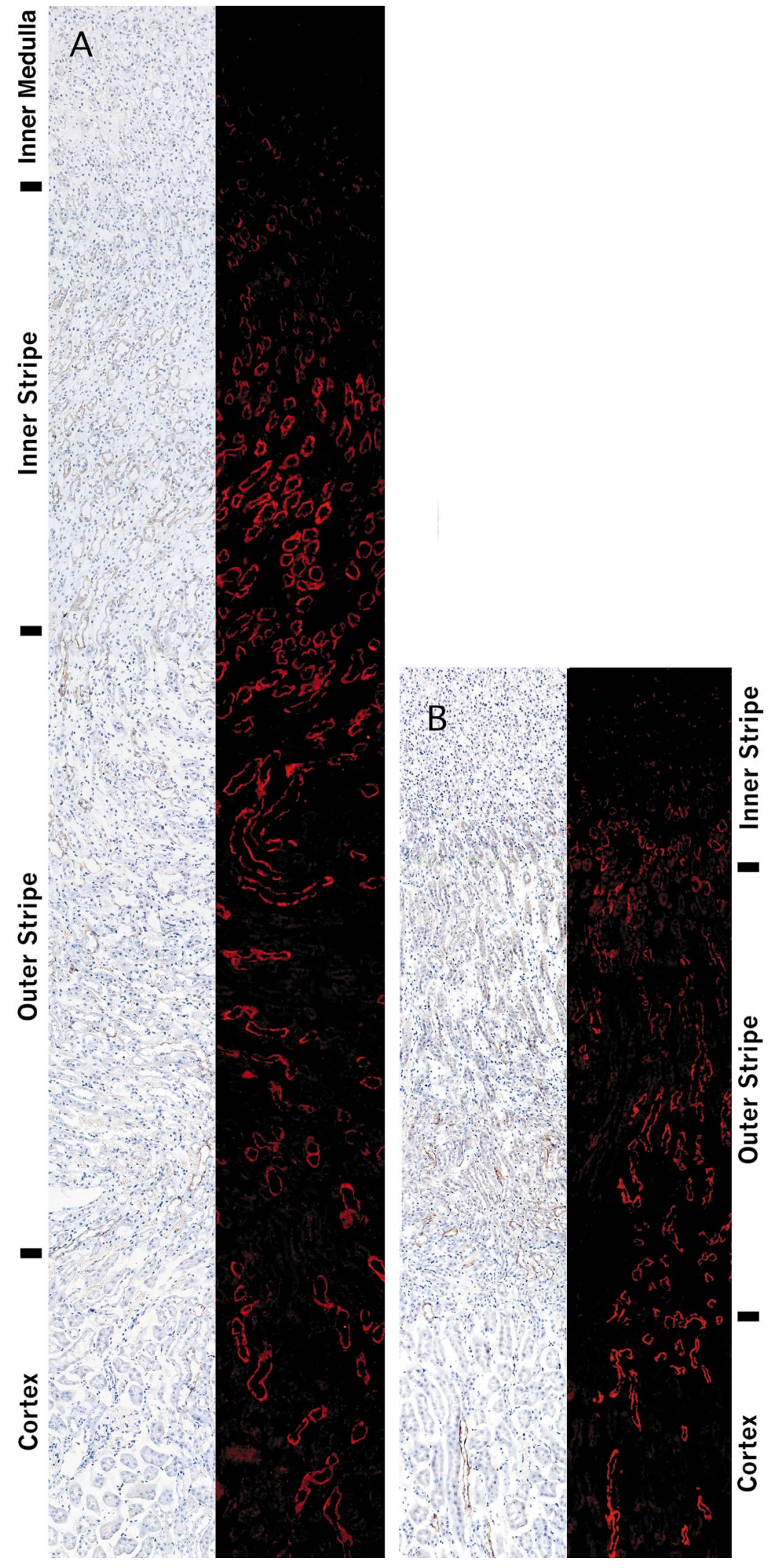

Fig. 3. AQP3-immunocytochemistry on kangaroo rat and mouse kidney. Anti-AQP3 immunostaining was performed with the peroxidase/counter-staining method ( $A$ and $B$, left $)$ and immunofluorescence ( $A$ and $B$, right). In kangaroo rat $(A), \mathrm{AQP} 3$ staining is strong in cortical and medullary collecting ducts and diminishes in the terminal portion of the inner stripe and the inner medulla. In mouse $(B)$, staining of AQP3 is strong in cortical collecting ducts, becomes weaker in medullary collecting ducts of the outer stripe, and is nearly absent in the inner stripe. copper specimen holders, and frozen in $\mathrm{N}_{2}$-cooled Freon 22. Frozen samples were transferred into a freeze-fracture apparatus (Cressington Scientific Instruments, Watford, UK). Samples were shaved with the microtome blade at $-145^{\circ} \mathrm{C}$ and under high vacuum ( $10^{-7}$ Torr $)$ until the thickness of the remaining tissue adhering to the copper support was $\sim 0.1$ $\mathrm{mm}$. A final knife pass was then carried out at a specimen temperature of $-120^{\circ} \mathrm{C}$ to produce the final fractured sur- 
Fig. 4. AQP4 and $\mathrm{H}^{+} / \mathrm{K}^{+}$-ATPase immunocytochemistry of gastric tissues. Anti-AQP4 (green) and anti- $\mathrm{H}^{+} / \mathrm{K}^{+}$. ATPase (red) staining of basolateral and apical plasma membranes of parietal cells in the desert rodent $(A)$ and mouse $(B)$ are shown. Bar $=15 \mu \mathrm{m}$.
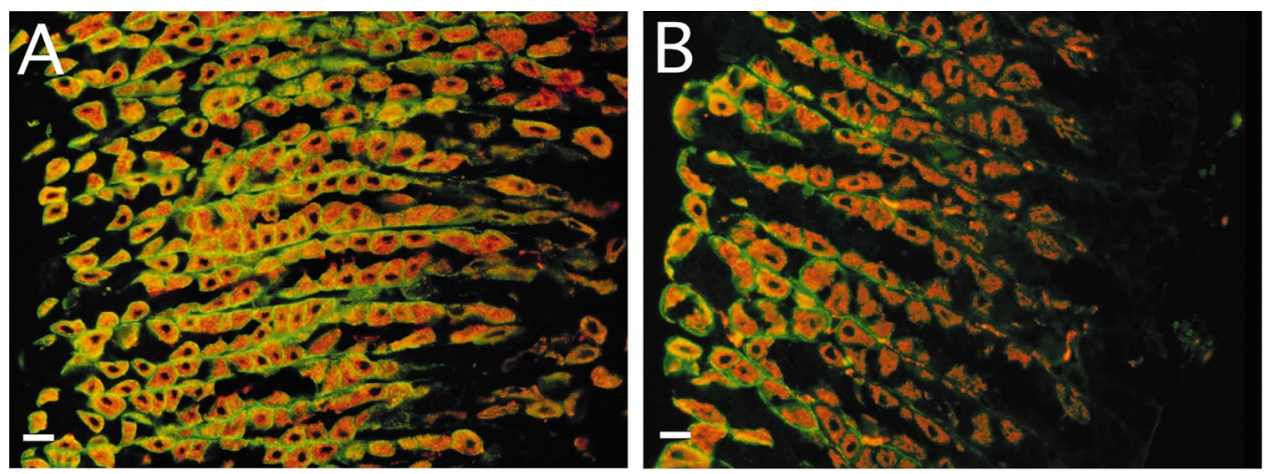

face. Samples were shadowed at an angle of $45^{\circ}$ with platinum ( $\sim 2$-nm thickness). For mechanical support of the platinum cast, a 3-nm carbon coat perpendicular to the fracture plane was then applied. After floating off in water, replicas were digested with sodium hypochlorite solution for $2 \mathrm{~h}$ and then rinsed with distilled $\mathrm{H}_{2} \mathrm{O}$. The replicas were picked up on electron microscope grids and examined in a Philips CM10 electron microscope (Mahwah, NJ).

\section{RESULTS}

All of the aquaporin antibodies used were cross reactive with their respective antigens in the kangaroo rat. Figure $1 A$ shows $\mathrm{AQP} 1$ staining in thin limbs of Henle and proximal tubules in a section of kangaroo rat kidney. This pattern of staining is similar to that seen in mice and rats $(5,20)$. Figure $1 B$ shows characteristic staining of collecting duct principal cells with anti-AQP2 antibodies, again in a pattern similar to that observed in other mammalian species (3). Typical basolateral staining of principal cells with anti-AQP3 antibodies is shown in Fig. $1 C$. Finally, and unexpectedly, AQP4 was undetectable in any cell type of the kangaroo rat kidney (Fig. $1 D$ ). The inner stripe of the kangaroo rat outer medulla is shown in Fig. $2 A$, double stained for the $31-\mathrm{kDa}$ subunit of the vacuolar $\mathrm{H}^{+}$ATPase and $\mathrm{AQP} 4$. Intercalated cells are stained by the $\mathrm{H}^{+}$ATPase antibody, but adjacent principal cells are not labeled for $\mathrm{AQP} 4$. A similar region from a mouse kidney is shown for comparison in Fig. $2 C$. In this case, principal cells show a strong basolateral staining for $\mathrm{AQP} 4$. Figure $2 B$ shows the outer stripe of the outer medulla of a kangaroo rat kidney. S3 segments that express gp330/megalin, a proximal tubule marker in the kidney, are negative for $\mathrm{AQP} 4$, in contrast to mouse kidney proximal tubules (Fig. 2D). In kangaroo rats, AQP3 staining was strong throughout the cortical and most regions of the medullary collecting ducts (Fig. 3A), in contrast to the situation in mice where inner stripe and inner medullary collecting ducts were more weakly stained for AQP3 than outer stripe and cortical collecting ducts (Fig. $3 B$ ).

To determine whether the absence of anti-AQP4 antibody staining in kangaroo rat kidneys was due to a lack of reactivity with the antigen in this species, we examined other tissues in which AQP4 is expressed. Figure $4 A$ shows that basolateral membranes (green) of gastric parietal cells of the kangaroo rat were strongly stained with the same anti-AQP4 antibody that failed to stain the kidney. Compared with mouse stomach, (Fig. 4B), the number of parietal cells stained seemed greater in the kangaroo rat. The identity of parietal cells was confirmed by double staining the sections with anti- $\mathrm{H}^{+} \mathrm{K}^{+}$-ATPase antibodies, which labeled the apical cananiculi (red).

Western blotting (Fig. 5) confirmed the absence of AQP4 in the kidney of the desert rodent but its presence in the stomach. When mouse kidney and stomach were compared with those of the desert rodent, the stomach of the kangaroo rat had the highest content of AQP4.

Another signature of AQP4 is its ability to form orthogonal arrays of intramembraneous particles (OAPs) seen by freeze-fracture electron microscopy (25, 26, 31). Freeze-fracture electron microscopy showed that these OAPs were not detectable in plasma membranes of principal cells from the kangaroo rat (Fig. 6).

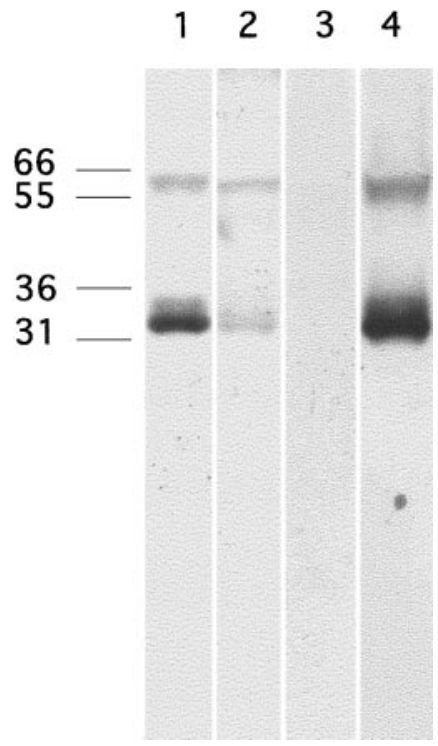

Fig. 5. AQP4-immunoblot analysis of kidney and stomach. Solubilized kidney and stomach tissues from mice (lanes 1 and 2, respectively) and kangaroo rats (lanes 3 and 4, respectively) were subjected to modified-SDS-NuPAGE and NuPAGE blotting. Fractions were probed with an anti-AQP4 antibody. Lane 1, mouse kidney (80 $\mu \mathrm{g}$ protein); lane 2 , mouse stomach (50 $\mu \mathrm{g}$ protein); lane 3 , kangaroo rat kidney (90 $\mu \mathrm{g}$ protein); lane 4 , kangaroo rat stomach (40 $\mu \mathrm{g}$ protein). 

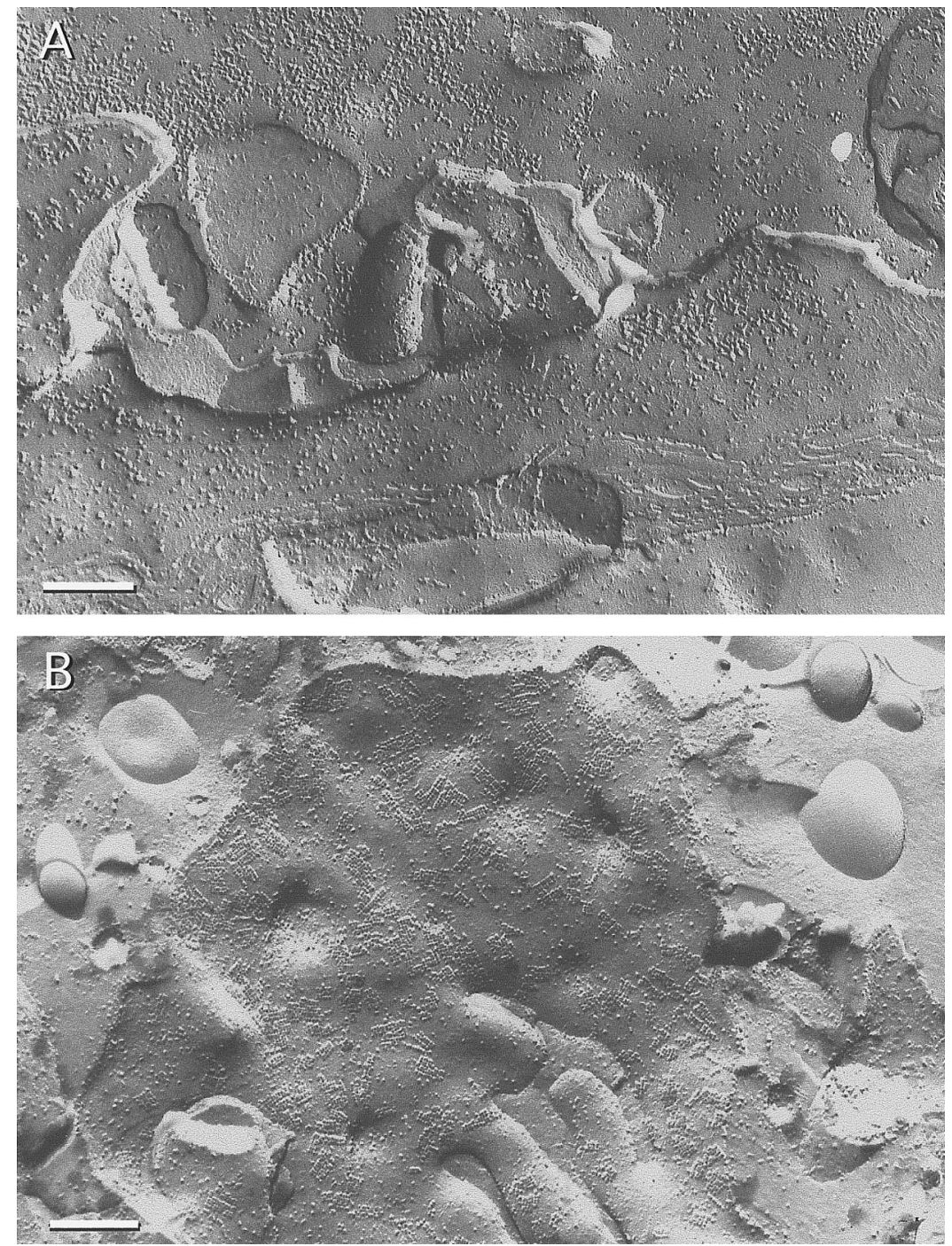

Fig. 6. Freeze-fracture electron microscopy of renal tissues. A: P-face of a lateral membrane of the principal cell found in kangaroo rat. Note the tight junction (bottom) that marks the transition between apical and basolateral membranes; the basolateral membrane does not contain orthogonal array particle aggregates (OAPs), whereas in $B$, OAPs in the basolateral membrane of a mouse principal collecting duct cell are evident. Bars $=250 \mathrm{~nm}$.
However, some patches or clusters of irregularly arranged intramembraneous particles (IMPs) could be detected. These clusters (but not the OAPs) were also found in basolateral membranes of principal cells of AQP4 knockout mouse (not shown; cf. Ref. 25) and probably reflect the presence of another water channel, AQP3, in these membrane domains.

In situ hybridization experiments, however, clearly demonstrated the presence of AQP4 mRNA in collecting duct principal cells of the kangaroo rat. Figure $7 \mathrm{~A}$ demonstrates specific staining of collecting duct cells, and, to a lesser extent, in proximal tubules of the S3 segment. Figure $7 B$ shows a similar but stronger staining of AQP4 mRNA in principal cells and proximal tubules of the S3 segment of the mouse kidney. The specificity of the probe used was demonstrated by preincubation of the anti-sense probe with sense cRNA (Fig. 7, $C$ and $D$ ) or hybridization of sections with digoxigenin-labeled sense cRNA (not shown). Conversely, Northern blot analysis with a DNA probe indicated that AQP4 RNA was below detectable levels in total RNA extracts of kidneys of the desert rodent, while it was observed in the stomach (Fig. $8 A$, lane 1 vs. lane 2). A strong signal was found in the mouse kidney, but the mouse stomach gave a signal weaker than that of the kangaroo rat stomach (Fig. 8A, lanes 3 and 4). In agreement with the in situ data, however, RT-PCR indicated the occurrence of AQP4 mRNA in the kangaroo rat kidney (Fig. $8 C$, lane 1), but the signal was less intense than that obtained from the mouse kidney (Fig. 8C, lane 3). Reprobing the Northern membranes with GAPDH (Fig. $8 B$ ) indicated that RNA in each of the samples was present and sufficiently intact to conclude that expression of AQP4 RNA in the kangaroo rat kidney is suppressed compared with AQP4 RNA expression in the mouse kidney.

\section{DISCUSSION}

The major and surprising finding of this study is that AQP4 water channel protein is not expressed at detectable levels in the kidneys of the desert kangaroo $\operatorname{rat} D$. merriami. This absence by immunocytochemistry and Western blotting was corroborated by the lack of OAPs 
Fig. 7. In situ hybridization of renal tissues. $A$ and $B$ : hybridization with anti-sense digoxigenin labeled AQP4 cRNA of medullary sections showing blue/purple color in principal cells $(*)$ of collecting ducts and in proximal tubule (+) of the S3 segment. $C$ and $D$ : in situ hybridization experiments of similar sections of which anti-sense probe was preincubated with sense AQP4 cRNA. $A$ and $C$ : desert rodent. $B$ and $D$ : mouse. Bar $=15 \mu \mathrm{m}$.

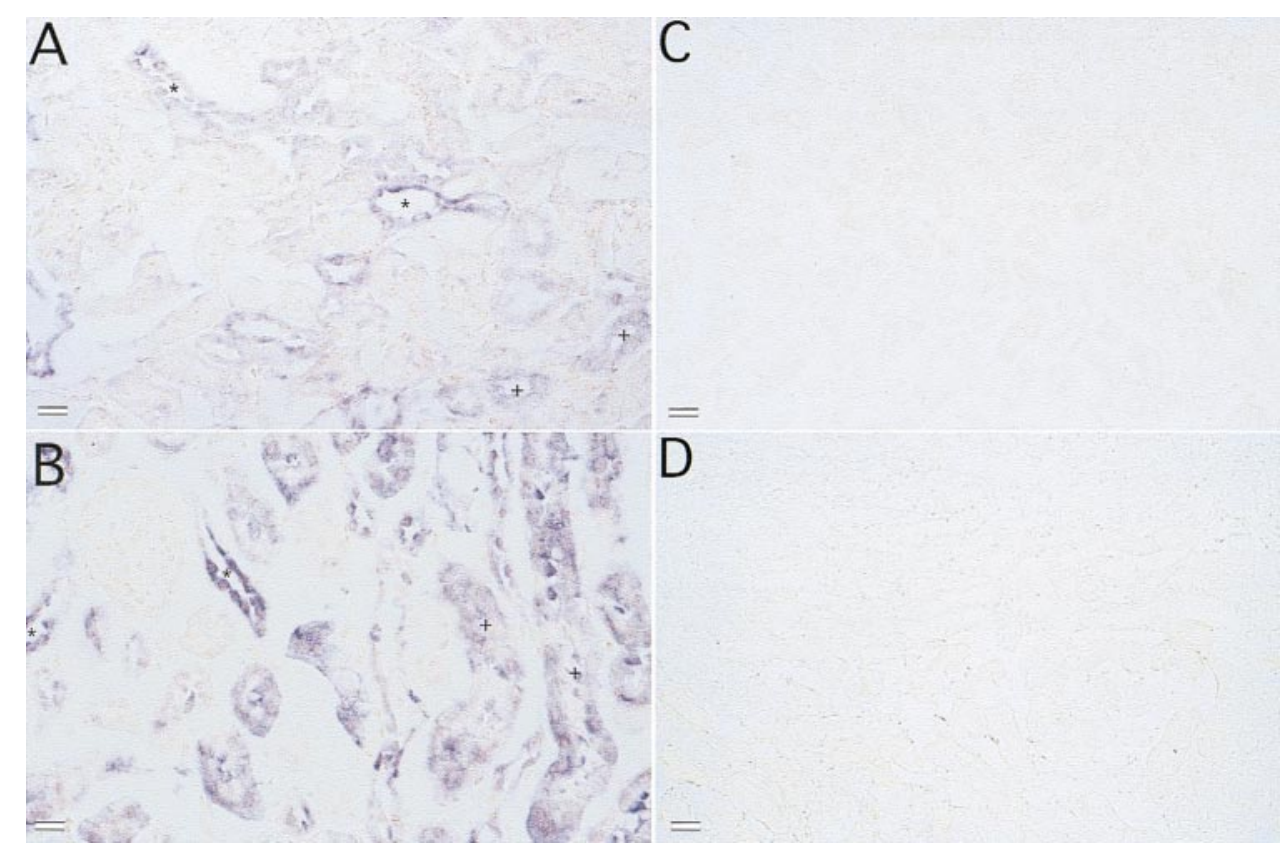

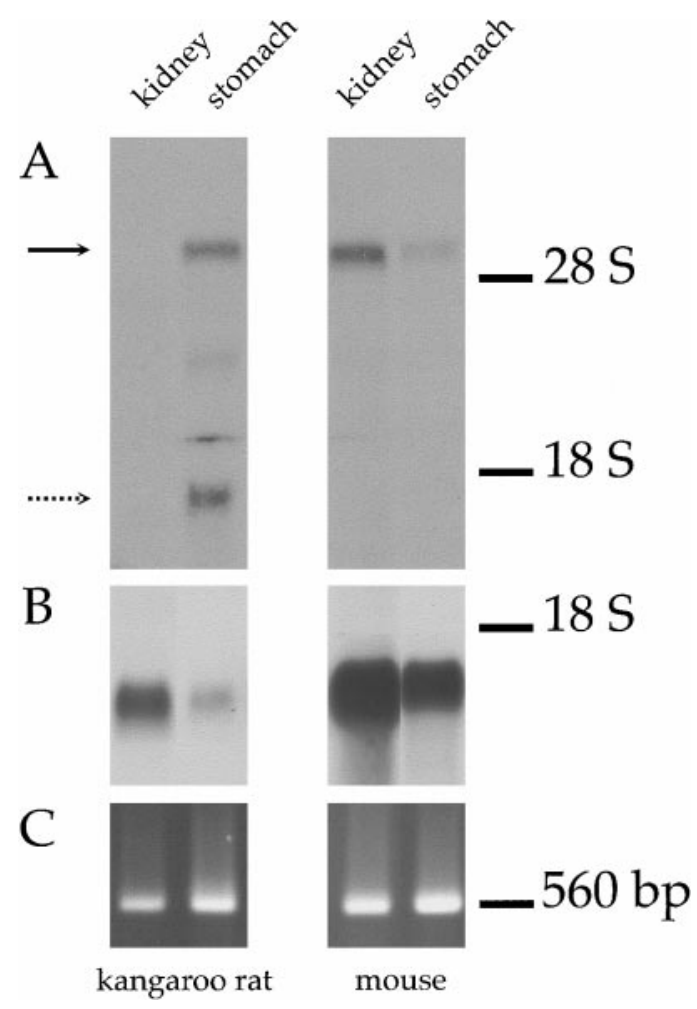

Fig. 8. Northern hybridization and RT-PCR of renal and gastric tissues. A: hybridization of a radioactively labeled AQP4 DNA probe with $10 \mu \mathrm{g}$ of total RNA extracts of renal (lanes 1 and 3) and gastric (lanes 2 and 4) tissues. The arrow (top) indicates that AQP4 RNA is at least $5 \mathrm{~kb}$ in size, whereas the occurrence of another band (dashed arrow) in the stomach sample from the kangaroo rat, lane 2, may represent a spliced form of AQP4 RNA (Fang P and Van Hoek AN, unpublished observations). $B$ : the same RNA extracts tested for glyceraldehyde-3-phosphate dehydrogenase (GAPDH) reactivity. $C$ : RT-PCR of total RNA extracts using species-specific primers. in kidney epithelial cell membranes on examination by freeze-fracture electron microscopy. In contrast to the absence of AQP4, another principal cell water channel, AQP3, was highly expressed in all regions of the collecting duct system; in mice and rats a much lower level of expression of AQP3 is found in the inner medulla. Taken together, these data show that the rodent D. merriami has a tissue-specific knockout of AQP4 from the kidney, indicating that AQP4 is not necessary for this species to concentrate its urine to levels of $\sim 5,000 \mathrm{mosmol} / \mathrm{kgH}_{2} \mathrm{O}$. Instead, AQP3 might be the important basolateral water channel involved in urinary concentration, because this aquaporin was more extensively expressed in kangaroo rats than in other rodent species examined so far.

The apparently contradictory results of RT-PCR and in situ hybridization vs. Northern blotting of the kangaroo rat kidney is probably a reflection of the variable sensitivities of these techniques for mRNA detection. Northern blots were performed on total RNA extracted from whole kidneys without amplification, whereas RT-PCR involves amplification steps. Also in situ hybridization can detect RNA that is expressed in a subset of cells in a given tissue or organ. We conclude from these data that AQP4 RNA is expressed (but at lower levels than in mouse kidney) in principal cells and in proximal tubule (S3 segment) epithelial cells of the kangaroo kidney. Furthermore, AQP4 RNA expression is not translated into protein. Thus the combination of low abundance of AQP4 RNA and absence of AQP4 protein contribute to the kidney-specific AQP4 knockout phenotype of the kangaroo rat. Differences between protein and mRNA levels are not uncommon $(10,13,18,24)$, indicating the importance of performing parallel protein and mRNA assays when changes in gene expression in a physiological and functional context are interpreted. 
One potential concern was that the lack of immunostaining/Western blotting of kidney was due to the use of an antibody that did not cross react with AQP4 of the desert kangaroo rat. However, by screening other tissues, strong anti-AQP4-antibody staining was found on basolateral membranes of parietal cells in the stomach and glial cells of the brain, as previously found in rat and mouse $(8,9,17,22)$. Therefore, whereas it remains theoretically possible that the kidney expresses a different form of AQP4, the antibody used in this study can readily detect AQP4 in other tissues of the kangaroo rat.

An obligatory role for $\mathrm{AQP} 4$ in urinary concentration is doubtful based on our present data. Studies on AQP4 knockout mice also did not indicate a critical role for AQP4 in urinary concentration (25), acidification of the stomach lumen, or skeletal muscle function (30). However, deletion of AQP4 seems to reduce brain edema after acute water intoxication and ischemic stroke (17), suggesting a negative role for AQP4 in this context. It has been reported that protein kinase $\mathrm{C}$ activators strongly stimulate the phosphorylation of AQP4 when expressed in Xenopus oocytes and that phosphorylation inhibits AQP4 activity in a dose-dependent manner (11). Unlike other mammalian aquaporins, the water channel pore within the AQP4 protein could be gated, thus providing a potential modulatory role for AQP4 under some, but not all, physiological circumstances.

The physiology of water transport with respect to urinary concentrating ability most likely involves AQP1, AQP2, and AQP3, but not AQP4. Urinary concentration capacity relies on the presence of a gradient of urea that serves as an osmotic driving force for reabsorption of water. Countercurrent flow and the presence of urea permeability pathways are required to maintain the urea gradient, and active transport of $\mathrm{NaCl}$ in thick ascending limbs is thought to be a major driving force for this process. However, with emerging data from novel AQP knockout mice (27), functional studies of oocyte-expressing aquaporins $(23,31)$, as well as data examining the roles of transporters other then aquaporins (7), existing models may need to be reevaluated. The requirement for two water channels, $\mathrm{AQP} 3$ and $\mathrm{AQP} 4$, in principal cell basolateral membranes is unclear. AQP3 transports not only water, but also urea and glycerol $(14,23,29,32)$. Some reports have indicated that AQP3 is a relatively poor water channel, whereas it has a substantial permeability to urea and glycerol. In contrast, AQP4 is a very effective water channel, but is not permeable to urea or glycerol. It is of interest that AQP3 expression is reduced in the inner medulla of mice and rats, where interstitial urea concentration is the highest, whereas it is abundantly expressed in this region in kangaroo rats.

Whereas the functional role of AQP4 in the kidney remains to be determined, it is of interest that kangaroo rats become bloated when allowed unlimited access to water (Tracy R and Walsberg G, unpublished observations). No change in AQP4 expression was detected in these water-loaded animals, even after $4 \mathrm{wk}$ of exposure to water. This observation may indicate that AQP4 is in some way involved in water clearance. However, the absence of AQP4 in the kidneys of these animals clearly indicates that this basolateral water channel is not necessary for urinary concentration.

This work was supported by National Institute of Diabetes and Digestive and Kidney Diseases Grants RO1-DK-55864 (A. N. Van Hoek) and DK-38452 (A. N. Van Hoek and D. Brown). R. Tracy and G. E. Walsberg were supported by National Science Foundation Grant IBN 9725211. A. Makkinje was supported by US Public Health Service Grant KO1 DK-02655.

\section{REFERENCES}

1. Beitz E and Schultz JE. The mammalian aquaporin water channel family: a promising new drug target. Curr Med Chem 6: 457-467, 1999

2. Borgnia M, Nielsen S, Engel A, Agre P. Cellular and molecular biology of the aquaporin water channels. Annu Rev Biochem 68: 425-458, 1999.

3. Brown D, Katsura T, Kawashima M, Verkman AS, and Sabolic I. Cellular distribution of the aquaporins: a family of water channel proteins. Histochem Cell Biol 104: 1-9, 1995.

4. Chou CL, Knepper MA, Hoek AN, Brown D, Yang B, Ma T, and Verkman AS. Reduced water permeability and altered ultrastructure in thin descending limb of Henle in aquaporin-1 null mice. J Clin Invest 103: 491-496, 1999.

5. Chou CL, Ma T, Yang B, Knepper MA, and Verkman AS. Fourfold reduction of water permeability in inner medullary collecting duct of aquaporin-4 knockout mice. Am J Physiol Cell Physiol 274: C549-C554, 1998.

6. Engel A, Fujiyoshi Y, and Agre P. The importance of aquaporin water channel protein structures. EMBO J 19: 800-806, 2000.

7. Fernandez-Llama P, Andrews P, Ecelbarger CA, Nielsen S, and Knepper M. Concentrating defect in experimental nephrotic syndrome: altered expression of aquaporins and thick ascending limb $\mathrm{Na}^{+}$transporters. Kidney Int 54: 170-179, 1998.

8. Frigeri A, Gropper MA, Turck CW, and Verkman AS. Immunolocalization of the mercurial-insensitive water channel and glycerol intrinsic protein in epithelial cell plasma membranes. Proc Natl Acad Sci USA 92: 4328-4331, 1995.

9. Fujita A, Horio Y, Nielsen S, Nagelhus EA, Hata F, Ottersen OP, and Kurachi Y. High-resolution immunogold cytochemistry indicates that AQP4 is concentrated along the basal membrane of parietal cell in rat stomach. FEBS Lett 459: 305309, 1999.

10. Graumann PL and Marahiel MA. A superfamily of proteins that contain the cold-shock domain. Trends Biochem Sci 23: 286-290, 1998 .

11. Han Z, Wax MB, and Patil RV. Regulation of aquaporin-4 water channels by phorbol ester-dependent protein phosphorylation. J Biol Chem 273: 6001-6004, 1998.

12. King LS, Yasui M, and Agre P. Aquaporins in health and disease. Mol Med Today 6: 60-65, 2000.

13. Kornitzer D and Ciechanover A. Modes of regulation of ubiquitin-mediated protein degradation. J Cell Physiol 182: $1-11,2000$.

14. Kuwahara M, Gu Y, Ishibashi K, Marumo F, and Sasaki S. Mercury-sensitive residues and pore site in AQP3 water channel. Biochemistry 36: 13973-13978, 1997.

15. Ma T, Song Y, Yang B, Gillespie A, Carlson EJ, Epstein CJ, andVerkman AS. Nephrogenic diabetes insipidus in mice lacking aquaporin-3 water channels. Proc Natl Acad Sci USA 97: 4386-4391, 2000.

16. Ma T, Yang B, Gillespie A, Carlson EJ, Epstein CJ, and Verkman AS. Severely impaired urinary concentrating ability in transgenic mice lacking aquaporin-1 water channels. J Biol Chem 273: 4296-4299, 1998.

17. Manley GT, Fujimura M, Ma T, Noshita N, Filiz F, Bollen AW, Chan P, and Verkman AS. Aquaporin-4 deletion in mice reduces brain edema after acute water intoxication and ischemic stroke. Nat Med 6: 159-163, 2000. 
18. Murer H, Forster I, Hernando N, Lambert G, Traebert M, and Biber J. Posttranscriptional regulation of the proximal tubule NaPi-II transporter in response to PTH and dietary $\mathrm{P}_{\mathrm{i}}$. Am J Physiol Renal Physiol 277: F676-F684, 1999.

19. Nielsen S, Kwon TH, Christensen BM, Promeneur D, Frokiaer J, and Marples D. Physiology and pathophysiology of renal aquaporins. J Am Soc Nephrol 10: 647-663, 1999.

20. Sabolic I, Valenti G, Verbavatz JM, Van Hoek AN, Verkman AS, Ausiello DA, and Brown D. Localization of the CHIP28 water channel in rat kidney. Am J Physiol Cell Physiol 263: C1225-C1233, 1992.

21. Sambrook J, Fritsch EF, and Maniatis T. Molecular Cloning: A Laboratory Manual (2nd ed.). Cold Spring Harbor, NY: Cold Spring Harbor Laboratory, 1989.

22. Terris J, Ecelbarger CA, Marples D, Knepper MA, and Nielsen S. Distribution of aquaporin-4 water channel expression within rat kidney. Am J Physiol Renal Fluid Electrolyte Physiol 269: F775-F785, 1995.

23. Tsukaguchi H, Shayakul C, Berger UV, Mackenzie B, Devidas S, Guggino WB, van Hoek AN, and Hediger MA. Molecular characterization of a broad selectivity neutral solute channel. J Biol Chem 273: 24737-24743, 1998.

24. Van der Velden AW and Thomas AA. The role of the $5^{\prime}$ untranslated region of an mRNA in translation regulation during development. Int J Biochem Cell Biol: 87-106, 1999.

25. Van Hoek AN, Ma T, Yang B, Verkman AS, and Brown D. Aquaporin-4 is expressed in basolateral membranes of proximal tubule S3 segments in mouse kidney. Am J Physiol Renal Physiol 278: F310-F316, 2000.

26. Verbavatz JM, Ma T, Gobin R, and Verkman AS. Absence of orthogonal arrays in kidney, brain and muscle from transgenic knockout mice lacking water channel aquaporin-4. J Cell Sci 110: 2855-2860, 1997.

27. Verkman AS. Lessons on renal physiology from transgenic mice lacking aquaporin water channels. J Am Soc Nephrol 10: 1126$1135,1999$.

28. Yamamoto T and Sasaki S. Aquaporins in the kidney: emerging new aspects. Kidney Int 54: 1041-1051, 1998.

29. Yang B, Brown D, and Verkman AS. The mercurial insensitive water channel (AQP-4) forms orthogonal arrays in stably transfected Chinese hamster ovary cells. J Biol Chem 271: 45774580, 1996.

30. Yang B, Verbavatz JM, Song Y, Vetrivel L, Manley G, Kao WM, Ma T, and Verkman AS. Skeletal muscle function and water permeability in aquaporin-4-deficient mice. Am J Physiol Cell Physiol 278: C1108-C1115, 2000.

31. Yang B and Verkman AS. Water and glycerol permeabilities of aquaporins 1-5 and MIP determined quantitatively by expression of epitope-tagged constructs in Xenopus oocytes. $J$ Biol Chem 272: 16140-16146, 1997.

32. Zeuthen T and Klaerke DA. Transport of water and glycerol in aquaporin 3 is gated by $\left.\mathrm{H}^{+}\right)$. J Biol Chem 274: 21631-21636, 1999.

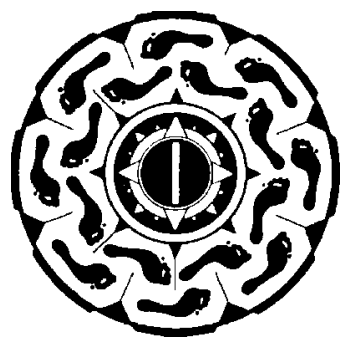

